Hal.

ARTIKEL ASLI

\title{
PERBEDAAN BENTUK LUKISAN SIDIK JARI, RIDGE COUNT, PALMAR PATTERN DAN SUDUT A-T-D ANTARA ORANG TUA ANAK SUMBING DENGAN ORANG TUA ANAK NORMAL DI TIMOR TENGAH SELATAN, NUSA TENGGARA TIMUR
}

\author{
Vincentia Maria Iriane*, Pudjo Sanjoto**, Retno M. Loekito** \\ * Mahasiswa Fakultas Kedokteran Unibraw \\ ** Laboratorium Anatomi Fakultas Kedokteran Unibraw
}

\begin{abstract}
The skin and lip-palate are formed nearly at the same period. They might be influenced by the similar genetic factor and environment. The objective of this research is to find the difference of dermatoglyphi between cleft-lip children's parents and normal childern's parents. The research is an analytical observation. It takes 50 samples of cleft-lip children's parents and 50 samples of normal children's parents. Each sample is classified into two groups, that is, (25) fathers and (25) mothers. Finger pattern, ridge count, palmar patern and a-t-d angle are dermatoglyphi variables to be measured. He result shows that: (1) The relationship between father's dermatoglifi and cleft-lip children is stronger than that between mother's dermatoglifi and cleft-lif childern. (2) The percentage of whorl (W) pattern is higher in cleft-lip children's parents; ehile the percentage of ulnar loop (UL)pattern is higher in normal children's parents. (3) The ridge count of cleft-lip children's fathers is normally higher than that of normal children's fathers. (4) There is no difference found in palmar pattern between cleft-lip children'parents and normal children's parents. (5) A-t-d angle of the cleft lips children's fathers is bigger than that of normal children's fathers. (6) Cleft lips in South East Timor, East Nusa Tenggara is ancertrally inherited.

Key words: Dermatoglyphies, cleft lip patients parent
\end{abstract}

\section{ABSTRAK}

Pembentukan kulit dan bibir-palatum terjadi dalam rentang waktu yang relatif bersamaan. Keduanya mungkin dipengaruhi faktor genetik dan lingkungan yang sama. Penelitian ini bertujuan mencari perbedaan dermatoglifi antara orang tua anak sumbing dengan orang tua anak normal. Penelitian dilakukan secara observasional analitik. Sampel terdiri dari 50 orang tua anak sumbing dan 50 orang tua anak normal, yang masing-masing dikelompokkan lagi menjadi 2, yaitu 25 ayah dan 25 ibu. Variabel yang diukur adalah dermatoglifi, yang meliputi bentuk lukisan sidik jari, ridge count, palmar pattern dan sudut a-t-d. Hasil penelitian ini menunjukkan bahwa: (1) Hubungan dermatoglifi ayah dengan kejadian sumbing pada anak lebih kuat dibandingkan hubungan dermatoglifi ibu dengan kejadian sumbing pada anak. (2) Prosentase pola whorl (W) lebih besar pada orang tua anak sumbing; prosentase pola ulnar loop (UL) lebih besar pada orang tua anak normal. (3) Rata-rata ridge count pada ayah anak sumbing lebih besar dari ayah anak normal. (4) Tidak ada perbedaan palmar pattern antara orang tua anak sumbing dengan orang tua anak normal.(5) Sudut a-t-d pada ayah anak sumbing lebih tumpul daripada ayah anak normal. (6) Kejadian sumbing di Timor Tengah Selatan (TTS), Nusa Tenggara Timur (NTT) diwariskan secara familial.

Kata kunci: Sidik jari, orang tua anak sumbing

\section{PENDAHULUAN}

Pada kulit jari tangan, telapak tangan, jari kaki dan telapak kaki terdapat sulur-sulur yang menimbulkan pola gambaran tertentu yang disebut dermatoglifi $(1,2)$. Dermatoglifi tidak akan berubah seumur hidup (3). Antara satu orang terhadap yang lain bahkan antar jari pada seorangpun tidak mungkin ada yang sama persis.

Dermatoglifi mulai terbentuk pada awal bulan kedua perkembangan embrio dan telah terbentuk secara sempurna pada minggu ke-17. Pembentukan dermatoglifi ini ditentukan oleh faktor genetik dan lingkungan embrio $(4,5)$. Bibir dan palatum mulai terbentuk pada minggu ke-6 dan telah terbentuk secara sempurna pada minggu ke-11. Kegagalan fusi pada pembentukan bibirpalatum menyebabkan terbentuknya celah (cleft). Kelainan ini disebut dengan sumbing. Faktor yang menjadi penyebab kelainan bawaan ini adalah faktor genetik, lingkungan, atau keduannya (6).
Pembentukan kulit dan pembentukan bibir-palatum terjadi pada waktu yang relatif sama sehingga keduanya bisa saja dipengaruhi oleh faktor internal (genetik) dan eksternal (lingkungan) yang sama. Dan tidaklah menutup kemungkinan bahwa insiden sumbing yang terjadi pada anaknya disebabkan karena mutasi genetik yang terjadi pada orang tuanya atau bahkan 2 generasi di atasnya. Terjadinya mutasi genetik ini juga akan mempengaruhi dermatoglifi.

Tujuan dari penelitian ini adalah untuk mengetahui perbedaan dermatoglifi (bentuk lukisan sidik jari, ridge count, palmar pattern, besar sudut a-t-d) antara orang tua anak sumbing dengan orang tua anak normal.

\section{METODE DAN CARA PENELITIAN}

Penelitian ini dilaksanakan dalam rancang bangun penelitian observasional analitik. Populasi penelitian ini adalah 
Hal.

orang tua anak sumbing dan orang tua anak normal di Timor Tengah Selatan (TTS), Nusa Tenggara Timur (NTT).

Dalam penelitian ini, sampel yang digunakan 50 orang tua anak sumbing (25 ayah dan $25 \mathrm{ibu}$ ). Data sekunder yang telah diperoleh dibagi menjadi 2 kelompok, yaitu data dermatoglifi orang tua anak sumbing dan data dermatoglifi orang tua anak normal.

Kemudian dengan menggunakan kaca pembesar dilakukan pengamatan lebih lanjut untuk mendapatkan 1) bentuk lukisan sidik jari pada tiap jari kedua tangan yang meliputi a) W (whorl) dimana lukisannya berupa sulur-sulur yang membentuk putaran atau kelokan spiral seperli gelung serta memiliki dua triradius (pertemuan 3 sulur), b) RL (radial loop) dimana lukisannya berupa sulur-sulur yang membentuk belokan atau lengkung tajam yang membuka ke tepi radial serta memiliki satu triradius, c) UL (ulnar loop) dimana lukisannya berupa sulur-sulur yang membentuk belokan atau lengkung tajam yang membuka ke tepi ulnar serta memiliki satu triradius, d) A (arch) dimana sulursulurnya membentuk garis melengkung menyerupai busur serta tidak memiliki triradius, 2) ridge count pada tiap jari kedua tangan, diperoleh dengan membuat garis antara triradius dan titik pusat terlebih dahulu kemudian dihitung garis-garis yang melintasinya, 3) ada atau tidak pola atau bentuk lukisan pada tiap area palmar (telapak tangan), 4) sudut a-t-d (sudut yang dibentuk antara garis yang ditarik dari triradius a ke triradius $t$ dengan garis yang ditarik dari triradius $t$ ke triradius $d$ ) diukur dengan menggunakan busur derajat.

Dari data dermatoglifi orang tua anak sumbing dan orang tua anak normal 1) dihitung frekuensi dan prosentase kemunculan W, RL, UL, A untuk tiap jari kemudian dianalisa dengan uji chisquare, 2) dihitung rata-rata (mean) dan standart deviasi dari hasil penghitungan ridge kemudian dianalisa dengan $T$-test, 3) dihitung prosentase ada dan tidak pola untuk tiap-tiap area interdigital, thenar, dan hypothenar kemudian dianalisa dengan uji chi-square, 4) dilakukan pengukuran besar sudut a-t-d, dihitung rata-rata (mean) dan standart deviasinya kemudian dianalisa dengan $T$ test.

\section{HASIL PENELITIAN}

Tabel 1. Hasil Analisa Bentuk Lukisan Sidik Jari antara Orang tua Anak Sumbing dengan Orang tua Anak Normal dengan Uji Chi-square

\begin{tabular}{|c|c|c|c|c|}
\hline \multirow[b]{2}{*}{ Tangan } & \multirow[b]{2}{*}{ Jari } & \multicolumn{3}{|c|}{$X^{2}$} \\
\hline & & $\begin{array}{c}\text { Orang tua } \\
\text { anak sumbing } \\
\text { dengan orang } \\
\text { tua anak } \\
\text { normal }\end{array}$ & $\begin{array}{c}\text { Ayah anak } \\
\text { sumbing } \\
\text { dengan ayah } \\
\text { anak normal }\end{array}$ & $\begin{array}{l}\text { ibu anak } \\
\text { sumbing } \\
\text { dengan ibu } \\
\text { anak normal }\end{array}$ \\
\hline Kiri+kanan & 10 jari & 19,952 * & $15,850^{*}$ & $12,124^{*}$ \\
\hline $\mathrm{K}$ & 5 & 1,328 & 0,5 & 1,086 \\
\hline I & 4 & 0 & 0,802 & 0,724 \\
\hline $\mathrm{R}$ & 3 & 1,841 & 1,389 & 1,032 \\
\hline I & 2 & 3,243 & 1,545 & 2,883 \\
\hline & 1 & 14,070 * & $7,657^{*}$ & $9,710^{*}$ \\
\hline $\mathrm{K}$ & 1 & 12,298 * & $9,704^{*}$ & 4,971 \\
\hline A & 2 & $9,454^{*}$ & $10,500^{*}$ & 2,468 \\
\hline $\mathrm{N}$ & 3 & 2,064 & 0,72 & 2,845 \\
\hline A & 4 & $4,167^{*}$ & 3,125 & 1,298 \\
\hline $\mathrm{N}$ & 5 & 0,060 & 0,925 & 2,380 \\
\hline
\end{tabular}

Keterangan: $5=$ jari kelingking

$4=$ jari manis

$3=$ jari tengah

$2=$ jari telunjuk

$1=$ ibu jari

* terdapat perbedaan bermakna

Tabel 2. Hasil Analisa Ridge Count antara Orang tua Anak Sumbing dengan Orang tua Anak Normal dengan $T$ tes.

\begin{tabular}{|c|c|c|c|c|}
\hline \multirow{2}{*}{ Tangan } & Jari & $\begin{array}{c}\text { Orang tua anak } \\
\text { sumbing } \\
\text { dengan } \\
\text { orang tua anak } \\
\text { normal }\end{array}$ & $\begin{array}{c}\text { Ayah anak sumbing } \\
\text { dengan } \\
\text { ayah anak normal }\end{array}$ & $\begin{array}{c}\text { ibu anak sumbing } \\
\text { dengan } \\
\text { ibu anak normal }\end{array}$ \\
\cline { 3 - 5 } Kiri+kanan & 10 jari & $4,246^{*}$ & $4,608^{*}$ & 1,135 \\
K & 5 & 0,918 & 0,952 & 0,319 \\
I & 4 & 0,725 & 1,207 & $-0,095$ \\
R & 3 & 0,841 & 1,122 & 0 \\
I & 2 & 0,624 & 1,325 & $-0,613$ \\
K & 1 & $2,767^{*}$ & 1,809 & 2,117 \\
A & 2 & $2,760 *$ & $2,906^{*}$ & 0,979 \\
N & 3 & $1,236^{*}$ & $2,111^{*}$ & $-0,389$ \\
A & 4 & 0,332 & 0,986 & $-0,595$ \\
N & 5 & $2,129^{*}$ & 1,527 & 1,463 \\
\hline
\end{tabular}

Keterangan: $5=$ jari kelingking

$4=$ jari manis

$3=$ jari tengah

$2=$ jari telunjuk

$1=$ ibu jari

* terdapat perbedaan bermakna

Tabel 3. Hasil Analisa Palmar Pattern antara Orang tua Anak Sumbing dengan Orang tua Anak Normal dengan Uji Chi-square.

\begin{tabular}{|c|c|c|c|c|}
\hline \multirow[b]{2}{*}{ Area } & \multirow[b]{2}{*}{ Tangan } & \multicolumn{3}{|c|}{$\mathrm{X}^{2}$} \\
\hline & & $\begin{array}{c}\text { Orang tua anak } \\
\text { sumbing dengan } \\
\text { orang tua anak } \\
\text { normal }\end{array}$ & $\begin{array}{c}\text { Ayah anak } \\
\text { sumbing dengan } \\
\text { ayah anak normal }\end{array}$ & \begin{tabular}{|c|} 
ibu anak \\
sumbing \\
dengan \\
ibu anak normal
\end{tabular} \\
\hline \multirow[t]{2}{*}{ Hypothenar } & Kiri & 2,8368 & 3,191 & 0,354 \\
\hline & Kanan & 3,092 & 2,083 & 1,020 \\
\hline \multirow[t]{2}{*}{ Thenar/ID1 } & & 0,198 & 0,802 & 2,913 \\
\hline & Kanan & 0 & 0 & 0 \\
\hline \multirow[t]{2}{*}{ ID2 } & & 0 & 0 & 0 \\
\hline & Kanan & 2,040 & 1,020 & 1,020 \\
\hline \multirow[t]{2}{*}{ ID3 } & & 0,088 & 0,595 & 0,222 \\
\hline & Kanan & 1,168 & 3,125 & 0,103 \\
\hline \multirow[t]{2}{*}{ ID4 } & Kiri & 0,190 & 0,095 & 0,095 \\
\hline & Kanan & 0,666 & 2 & 0,095 \\
\hline
\end{tabular}

Keterangan: ID1= Interdigital 1

ID2= Interdigital 2

ID3 = Interdigital 3

ID4= Interdigital 4

Maj. Kedok. Unibraw Vol. XIX, No.2, Agustus 2003 
Hal.

Tabel 4. Hasil Analisa Sudut A-t-d antara Orang tua Anak Sumbing dengan Orang tua Anak Normal dengan $T$ test.

\begin{tabular}{|l|c|c|c|}
\hline \multirow{2}{*}{ Tangan } & \multicolumn{3}{|c|}{$\mathrm{X}^{2}$} \\
\cline { 2 - 4 } & $\begin{array}{c}\text { Orang tua anak } \\
\text { sumbing dengan } \\
\text { orang tua anak } \\
\text { normal }\end{array}$ & $\begin{array}{c}\text { Ayah anak sumbing } \\
\text { dengan } \\
\text { ayah anak normal }\end{array}$ & $\begin{array}{c}\text { ibu anak sumbing } \\
\text { dengan } \\
\text { ibu anak normal }\end{array}$ \\
\hline Kiri & $3,227^{*}$ & $4,586^{*}$ & 0,434 \\
Kanan & $2,362^{*}$ & $3,542^{*}$ & $-0,143$ \\
\hline
\end{tabular}

Keterangan: * terdapat perbedaan bermakna

\section{PEMBAHASAN}

Berdasarkan literatur, aspek genetik sumbing yang sebenarnya masih diperdebatkan orang. Para ahli mengungkapkan pendapat yang berbeda-beda mengenai teori ini, antara lain pewarisan secara terangkai $X$ dan autosomal.

Dari hasil penelitian ternyata hubungan dermatoglifi dengan kejadian sumbing pada anak lebih kuat dibandingkan dengan hubungan dematoglifi ibu dengan kejadian sumbing pada anak. Hal ini tidak disebabkan karena autosom (bila diwariskan secara autosom maka kejadian sumbing akan disertai kelainan kongenital yang lain) maupun $X$-lingked recesif. Menurut teori $X$ lingked recesif terdapat tiga kemungkinan, yaitu:

Kemungkinan I:

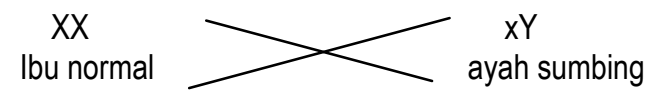
F1: $\quad X x$
$X Y$
Xx
$X Y$
o carrier $\delta^{7}$ norma
o carrie
§normal

Kondisi ini tidak mungkin terjadi sebab ayah menderita sumbing.

Kemungkinan II:

$$
\begin{gathered}
\text { Xx } \\
\text { Ibu carrier }
\end{gathered}
$$

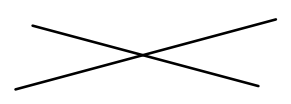

$\mathrm{xY}$ ayah sumbing
F1: $\quad X x$
q carrier
$\mathrm{XY}$
ônormal
$\mathrm{xx}$
q sumbing
$x Y$
$\widehat{\jmath}$ sumbing

Kondisi ini tidak mungkin terjadi sebab ayah menderita sumbing

Kemungkinan III:

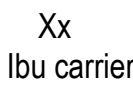

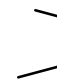

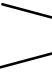

$X Y$ ayah normal
F1: $\quad X x$
$X Y$
$X X$
$\mathrm{xY}$
+ carrier
ônormal
q normal
ôssumbing

Kondisi ini juga tidak mungkin terjadi pada daerah TTS, NTT karena F1 menunjukkan hanya anak laki-laki yang menderita sumbing sedangkan pada daerah ini jumlah laki-laki dan perempuan sumbing hampir sama banyaknya (peluang laki-laki sumbing 0,345 ; peluang perempuan sumbing 0,342 ).

Dengan gugurnya kedua teori di atas, maka kejadian sumbing di TTS, NTT ini kemungkinan disebabkan karena multifaktorial.

Dari hasil analisa bentuk lukisan sidik jari ternyata prosentase pola Whorl (W) lebih besar pada orang tua anak sumbing dan prosentase pola Ulnar Loop (UL) lebih besar pada orang tua anak normal.

Dari hasil analisa ridge count didapatkan rata-rata ridge count pada ayah anak sumbing yang lebih besar dari ayah anak normal, sedangkan pada ibu tidak selalu demikian. Dari hasil analisa palmar pattern ternyata tidak didapatkan perbedaan bermakna antara orang tua anak sumbing dengan orang tua anak normal.

Dari hasil analisa sudut a-t-d ternyata perbedaan bermakna terdapat pada ayah saja, sedangkan pada ibu tidak. Hal ini menunjukkan bahwa hubungan ayah-anak lebih kuat dari pada ibu-anak. Hal ini sesuai dengan Loekito (1992) dalam "Hubungan Labiopalatoschisis dengan Konsanguitas dan Beberapa Ukuran Kepala", dimana ternyata lebar bigonial ayah saja yang berbeda sedangkan ibu tidak (6). Hal ini menunjukkan bahwa korelasi bentuk wajah ayah-anak lebih kuat daripada ibuanak. Sudut a-t-d pada ayah anak sumbing lebih tumpul. Deshmukh (1979) berpendapat bahwa adanya variasi dermatoglifi yang tidak simetris antara tangan kiri dan kanan menunjukkan bahwa kejadian tersebut diwariskan secara familial (7). Apabila kejadian itu disebabkan oleh teratogen, maka pola dermatoglifi akan simetris antara tangan kiri dan kanan. Dari hasil penelitian didapatkan adanya variasi dermatoglifi yang tidak simetris antara tangan kiri dan kanan. Sehingga dapat dikatakan bahwa kejadian sumbing di TTS,NTT memang diwariskan secara familial.

Pada penelitian selanjutnya pengamatan pola sidik jari dapat dilakukan pada ibu jari kiri terlebih dahulu, dengan tidak mengabaikan jari yang lain. Karena perbedaan bermakna terutama didapatkan pada jari tersebut.

\section{KESIMPULAN}

Kesimpulan yang diperoleh dari penelitian ini yaitu:

1. Hubungan dermatoglifi ayah dengan kejadian sumbing pada anak lebih kuat dibandingkan hubungan dermatoglifi ibu dengan kejadian sumbing pada anak.

2. Prosentase pada whorl (W) lebih besar pada orang tua anak sumbing dan prosentase pola ulnar loop (UL) lebih besar pada orang tua anak normal.

3. Rata-rata ridge count pada ayah anak sumbing lebih besar dari ayah anak normal.

4. Tidak ada perbedaan palmar pattern antara orang tua sumbing dengan orang tua anak normal.

5. Sudut a-t-d pada ayah sumbing lebih tumpul daripada anak normal.

6. Kejadian sumbing di TTS, NTT diwariskan secara familial. 
Hal.

\section{SARAN}

Saran yang dapat dibuat dari penelitian ini adalah:

1. Penelitian lebih lanjut tetang hubungan dermatoglifi orang tua dengan kejadian sumbing pada anak, sampel dapat difokuskan pada pola dermatoglifi ayah.
2. Melakukan penelitian tentang kerusakan kromosom pada anak sumbing.

3. Mencari kelainan lain yang manifes selain sumbing.

4. Melakukan penelitian lebih lanjut tentang faktor lingkungan apa saja di TTS, NTT yang dapat menyebabkan kejadian sumbing.

5. Melakukan penelitian serupa di daerah lain.

6. Melakukan peneitian serupa terhadap kelainan kongenital lainnya, misalnya sindroma down, kelainan jantung kongenital.

\section{DAFTAR PUSTAKA}

1. Cummins, H., Finger Prints, Palms and Soles: An Introduction to Dermatoglyphic. New York: Dover Publication Inc. 1961: 3-88.

2. Hidayati, R.S., et all. Penelitian Pola Triradius Garis Simian pada Telapak Tangan Anak-anak Penderita Sindroma Down di Sumber Asih Jakarta. Majalah Kedokteran Indonesia. 1980: 30(8): 202.

3. Karjadi, M., Sidik Jari Sistem Henry. Bogor: Politeia. 1976: 2-38.

4. Moore, K. L., The Developing Human, Clinically Oriented Embryology $4^{\text {th }}$ Ed. Philadelphia: W.B. Sauders Company. 1982: 421-422.

5. Sadler, T. W., Langman's Medical Embryology $7^{\text {th }}$ Ed. Maryland: William and Wilkins Publisher. 1995: 368-369.

6. Loekito, R. M., Hubungan Labiopalatoschisis dengan Konsanguitas dan Beberapa Ukuran Kepala (disertasi). 1992: 9-54.

7. Deshmukh, R.N., et al. Dermatogliphics in Cleft Lip and Cleft Palate Anomaly: Fimilial and Teratogenic Groups. Indian J Med Res 70. 1979: 814-818.

8. Anonymous. Closing in On Clefting. 2002. Http://www.nidr.nih.gov/spectrum/NIDCR/1textsec6.htm. 